\title{
Review Article \\ From Prion Diseases to Prion-Like Propagation Mechanisms of Neurodegenerative Diseases
}

\author{
Isabelle Acquatella-Tran Van Ba, ${ }^{1,2,3}$ Thibaut Imberdis, ${ }^{1,2,3}$ and Véronique Perrier ${ }^{1,2,3}$ \\ ${ }^{1}$ Université Montpellier 2, 34095 Montpellier, France \\ ${ }^{2}$ Inserm, U710, 34095 Montpellier, France \\ ${ }^{3}$ EPHE, 75007 Paris, France
}

Correspondence should be addressed to Véronique Perrier; veronique.perrier@univ-montp2.fr

Received 17 May 2013; Revised 5 September 2013; Accepted 5 September 2013

Academic Editor: Roberto Chiesa

Copyright (C) 2013 Isabelle Acquatella Tran Van Ba et al. This is an open access article distributed under the Creative Commons Attribution License, which permits unrestricted use, distribution, and reproduction in any medium, provided the original work is properly cited.

\begin{abstract}
Prion diseases are fatal neurodegenerative sporadic, inherited, or acquired disorders. In humans, Creutzfeldt-Jakob disease is the most studied prion disease. In animals, the most frequent prion diseases are scrapie in sheep and goat, bovine spongiform encephalopathy in cattle, and the emerging chronic wasting disease in wild and captive deer in North America. The hallmark of prion diseases is the deposition in the brain of $\operatorname{Pr} \mathrm{P}^{\mathrm{Sc}}$, an abnormal $\beta$-sheet-rich form of the cellular prion protein $\left(\mathrm{PrP}^{\mathrm{C}}\right)(\operatorname{Prusiner}$ 1982). According to the prion hypothesis, $\operatorname{PrP}^{S c}$ can trigger the autocatalytic conversion of $\operatorname{PrP}^{\mathrm{C}}$ into $\operatorname{Pr} \mathrm{P}^{\mathrm{Sc}}$, presumably in the presence of cofactors (lipids and small RNAs) that have been recently identified. In this review, we will come back to the original works that led to the discovery of prions and to the protein-only hypothesis proposed by Dr. Prusiner. We will then describe the recent reports on mammalian synthetic prions and recombinant prions that strongly support the protein-only hypothesis. The new concept of "deformed templating" regarding a new mechanism of $\operatorname{PrP}^{\mathrm{Sc}}$ formation and replication will be exposed. The review will end with a chapter on the prion-like propagation of other neurodegenerative disorders, such as Alzheimer's and Parkinson's disease and tauopathies.
\end{abstract}

\section{The Story of the Prion Protein That Was Mistaken for a Virus}

Prion diseases and prion infectious agents [1] are among the most fascinating biological topics of the twentieth century and have been under the spotlight for the last 30 years, particularly due to the striking epidemic of bovine spongiform encephalopathy (BSE), which started in Great Britain in the mid-eighties and then spread to other European countries [2]. The transmission of the bovine prion agent to humans, possibly through consumption of prion-contaminated beef products, led to the emergence of a new human prion disease, named "variant" Creutzfeldt-Jakob disease (vCJD), in young people [3]. Recently, several cases of secondary human-tohuman transmission of vCJD through transfusion of prioncontaminated blood [4-6] have raised doubts within the scientific community about the safety of blood products and highlighted the crucial need of diagnostic tests for prion detection in blood. Currently, the development of reliable blood tests and of therapies is the main mission of scientists working in the prion field.

Historically, the infectious agent that causes prion diseases was supposed to be an atypical virus belonging to the category of "slow viruses" [7, 8]. Then, in 1967, Pattison and colleagues reported [9] that the scrapie agent was resistant to heat and formaldehyde, two treatments that inactivate most viruses, thus introducing a doubt about the true nature of this infectious agent. In addition, in 1967, Alper and colleagues showed that the scrapie agent was also resistant to ionizing radiations and UV light irradiation that normally inactivates nucleic acids, suggesting that it was probably devoid of nucleic acids [10]. Based on these intriguing experimental data, Griffith suggested that the scrapie agent could be a protein that self-replicates through autocatalytic conformational changes [11]. This audacious hypothesis retained the attention of Stanley Prusiner who purified the scrapie agent 
from the brain of scrapie-infected hamsters and reported that inactivation by physicochemical agents that destroy proteins abolished the infectivity of such purified preparations [12]. In 1982, he proposed the new term of "PRION," for "proteinaceous infectious only particle," to define this atypical agent. The revolutionary idea that a protein may act as a virus was unbelievable at that time and Stanley Prusiner had to struggle hard to convince the scientific community. His outstanding work on prions earned him the Nobel Prize of Medicine in 1997, although at that time the ground-breaking concept of proteinaceous infectious particles was not yet definitively proved.

\section{Prion Diseases: The Revolutionary Concept of Pathogenic Misfolded Proteins}

The prion protein $(\mathrm{PrP})$ is the main component of prion agents and, remarkably, can fold into different (normal or pathogenic) conformations that are thermodynamically stable [13]. $\mathrm{PrP}^{\mathrm{C}}$, the normal cellular isoform, is mostly folded into $\alpha$-helices [14] and is detergent-soluble and completely digested by proteinase $\mathrm{K}$. Conversely, $\operatorname{PrP}^{\mathrm{Sc}}$ (for scrapie form), the abnormally folded isoform, is mostly folded into $\beta$-sheets [15], which confer insoluble property in detergents, and is partially resistant to proteinase $\mathrm{K}$. Indeed, $\operatorname{Pr} \mathrm{P}^{\mathrm{Sc}}$ digestion by proteinase $\mathrm{K}$ produces an $\mathrm{N}$-terminally truncated fragment that begins around residue 90 and is commonly called PrP27-30. $\operatorname{PrP}^{\mathrm{Sc}}$ isoforms are the main constituent of amyloid plaques and of brain deposits in patients affected by CJD. For this reason, $\operatorname{PrP}^{\mathrm{Sc}}$ is considered as the main disease marker and is the reference for the histopathological analyses carried out to diagnose prion diseases.

How can prions multiply? In the original "protein-only" hypothesis proposed by Griffith and Prusiner [1, 11], $\operatorname{PrP}^{\mathrm{Sc}}$ can trigger the autocatalytic conversion of normal $\operatorname{PrP}^{\mathrm{C}}$ into $\operatorname{PrP}^{\mathrm{Sc}}$ and imprints its misfolded form to $\operatorname{PrP}^{\mathrm{C}}$, which in turn becomes pathological (Figure 1). This conversion process involves several $\mathrm{PrP}^{\mathrm{Sc}}$ intermediates that are generated through a complex oligomerization mechanism and then self-assembled into protofibrils, which in turn grow into amyloid fibrils $[16,17]$. Then, large fibrils can break naturally, producing small fragments, called seeds, that will propagate de novo the prion agent (seeding process) [18-20]. As both $\mathrm{PrP}^{\mathrm{C}}$ and $\mathrm{PrP}^{\mathrm{Sc}}$ are exposed at the cell surface and attached to the plasma membrane through a GPI anchor, they can propagate in tissues via cell-cell contacts $[21,22]$. Many recent lines of evidence indicate that the most neurotoxic species within this replication cycle are the small soluble oligomers rather than the large amyloid fibrils, which would serve as "reservoirs" to trap small neurotoxic species $[17,23,24]$.

\section{Development of Animal Models to Study Prion Infectivity}

The advent of molecular biology allowed the generation of cell (the neuroblastoma ScN2a cell line) and transgenic animal models [25-27] to investigate the molecular basis of prion replication, pathogenicity, and propagation. The crucial role of $\operatorname{PrP}$ was demonstrated using mice in which the gene coding for PrP (Prnp) was genetically ablated [28, 29]. These mice are resistant to prion inoculation and cannot propagate and replicate the infectious agent. Later on, Prnp knock out (using the cre/lox system) in the neurons of adult mice with early prion infection allowed demonstrating that the synaptic impairment, spongiosis, and behavioural deficits observed in these animals could be reversed [30]. Conversely, transgenic mice that harbour high copy numbers of a wildtype Prnp transgene develop a neurological syndrome that is similar in some aspects to prion disease, but they do not produce transmissible $\operatorname{PrP}^{\mathrm{Sc}}$ unless they are inoculated with prions [31]. For decades, no animal model of sporadic prion disease was available in which prions formed spontaneously from wild-type PrP and could be transmitted to other animals. Interestingly, spontaneous development of transmissible spongiform encephalopathy was observed in transgenic mice that overexpress a mouse-elk PrP chimeric molecule harbouring the two point mutations S170N and N174T that induce a rigidity of the $\beta 2-\alpha 2$ loop region [32]. The disease could be transmitted by intracerebral inoculation of brain homogenates from ill mice to tga20 mice that overexpress wild-type $\mathrm{PrP}$ and from them to wild-type mice. These findings illustrate the importance of $\operatorname{PrP} \beta 2-\alpha 2$ loop region. This region is rich in glutamine and asparagine residues, which are frequently encountered in amyloidogenic proteins, and may act as "hot spots" for protein aggregation. Recently, Watts et al. generated a transgenic mouse model, named $\operatorname{Tg}(B V P r P)$, that overexpresses wild-type bank vole (BV) PrP. These mice develop spontaneous CNS dysfunction between days 108 and 340 after birth that recapitulates the hallmarks of prion diseases [33]. Moreover, the disease could be transmitted to tga20 and wild-type mice by intracerebral injection of brain homogenates from ill $\operatorname{Tg}(\mathrm{BVPrP})$ animals. This is the first animal model showing that wild-type PrP can spontaneously form infectious prions in vivo and thus will be very useful for understanding the aetiology of sporadic prion diseases, such as sporadic CJD.

Several transgenic mice that overexpress the most frequent mutant PrP proteins, such as P101L PrP [34, 35] or PrP with a 9 octarepeat insertion in the N-terminus [36], were also generated. Although these mice succumb to spontaneous prion disease with various incubation times, they do not show all the biochemical and pathological features of prion diseases and often fail to transmit prion infectivity to wildtype animals. Recently, several transgenic mouse models of genetic prion diseases retained our interest:

(i) the $\operatorname{Tg}($ PG14) transgenic mice that express a mutant PrP with 14 octapeptide repeats [37] and present a progressive neurological disorder with ataxia, $\operatorname{PrP}$ deposition, and massive loss of cerebellar granule cells. They also display the main biochemical properties of $\operatorname{PrP}^{\mathrm{Sc}}$, such as partial resistance to proteinase $\mathrm{K}$, detergent insolubility and resistance to GPI-anchor cleavage by phospholipase;

(ii) the $\mathrm{Tg}(\mathrm{MHu} 2 \mathrm{ME} 199 \mathrm{~K})$ mouse model of genetic CJD, which is caused by the E200K substitution in human 


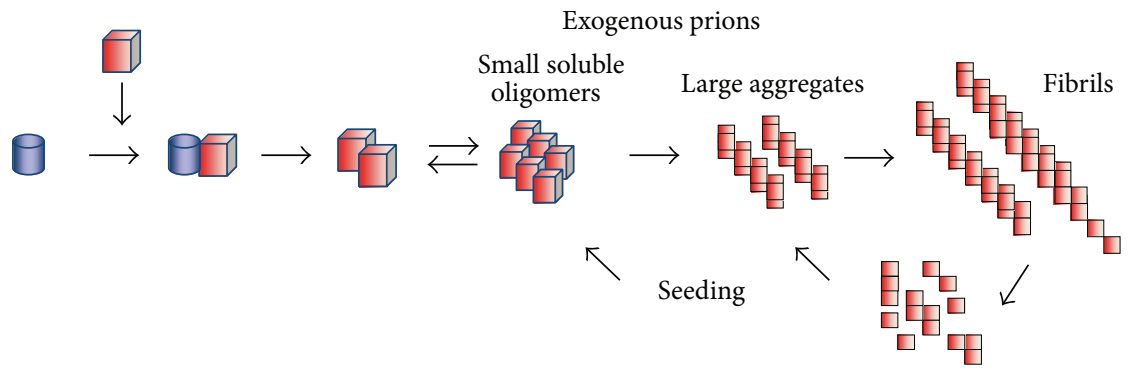

(a)

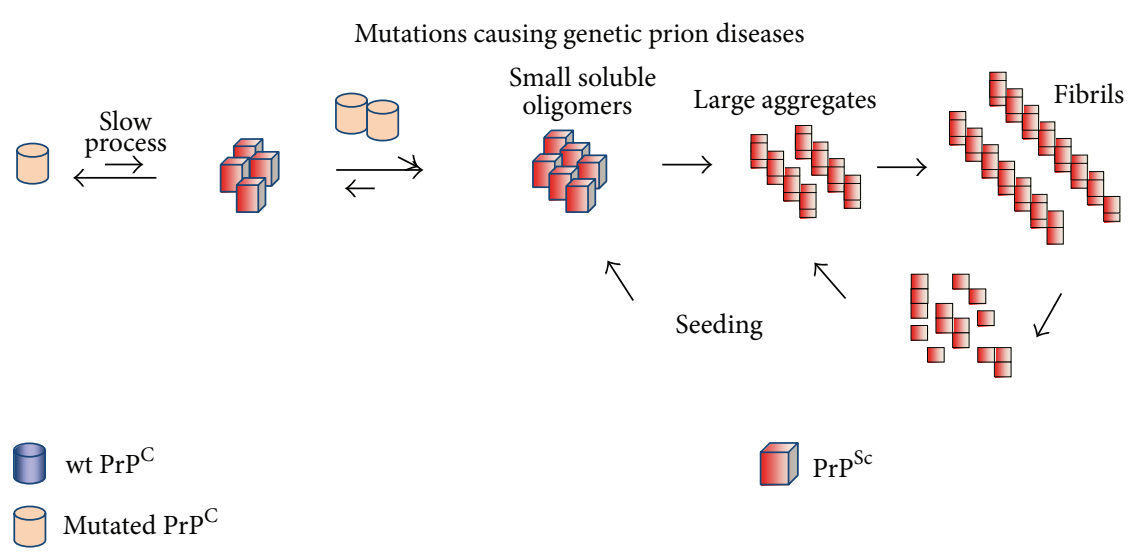

(b)

Figure 1: Proposed mechanisms of $\operatorname{PrP}^{\mathrm{C}}$ conversion into $\operatorname{PrP}^{\mathrm{Sc}}$, with exogenous (a) or genetic (b) prions. Wild-type $\operatorname{PrP} \mathrm{P}^{\mathrm{C}}$ is represented by a cylinder colored in blue, mutated $\operatorname{PrP}^{\mathrm{C}}$ is outlined in blue, and $\operatorname{PrP}^{\mathrm{Sc}}$ is represented by red square.

PrP. These animals express a chimeric mouse-human PrP harbouring the corresponding mouse E199K mutation (PrPMHu2ME199K) [38] and develop progressive neurodegenerative disease from 6 months of age. Histopathological analysis of their brain revealed the presence of astrocytic gliosis, spongiosis, and PK-resistant PrP deposits by western blotting. Importantly, brain extracts from $\mathrm{Tg}(\mathrm{MHu} 2 \mathrm{ME199K})$ sick mice transmitted the prion disease to wild-type animals [38];

(iii) the knock-in Ki-3F4-FFI mice that express a mutant PrP (D177N-M129-3F4 tagged) associated with fatal familial insomnia (FFI), a genetic human prion disease [39]. These mice present several neurological features (atrophied cerebellum, enlarged ventricles, and thalamus abnormalities) that are similar to those seen in humans with FFI. Surprisingly, these animals display a protease-sensitive PrP (sPrP) isoform, like patients with FFI, and the disease is transmissible to control $\mathrm{Ki}-3 \mathrm{~F} 4-\mathrm{WT}$ mice (wildtype Prnp) and to transgenic mice that overexpress wild-type $\operatorname{PrP}$ (tga20) [40]. The presence of PKsensitive $\mathrm{PrP}^{\mathrm{Sc}}$ in FFI mice supports recent findings showing that new PK-sensitive synthetic prions can be infectious [41], as well as the identification of a novel human prion disease called VPSPr (variably protease-sensitive prionopathy) [42], which is characterized by the presence of $\operatorname{PrP}^{\mathrm{Sc}}$ with highly variable PK resistance. As for all neurodegenerative disorders, it is important to generate the most appropriate animal models of the genetic forms of the disease in order to develop pertinent therapeutic strategies.

\section{Synthetic Mammalian Prions and Recombinant Prions: The Proof-of-Concept of the Protein-Only Hypothesis}

Despite the compelling evidence in favour of the prion hypothesis, some sceptics argued that the definite proof could be obtained only by producing in vitro the infectious material used for intracerebral inoculation starting from pure normal PrP, a technical feat that seemed impossible for many decades. A strong advance was the finding that recombinant hamster $\operatorname{PrP}(90-231)$ (recPrP, which corresponds to human PrP27-30) purified from $E$. coli under reducing conditions at $\mathrm{pH}>7$ has a high $\beta$-sheet content and low solubility, like $\mathrm{PrP}^{\mathrm{Sc}}$. Conversely, recPrP refolding by oxidation to form a disulphide bond produced a soluble protein with a high $\alpha$-helix content, similar to normal $\operatorname{PrP}^{\mathrm{C}}$ [43]. The ability of recPrP to adopt either an $\alpha$-helix- or $\beta$-sheet-rich conformation strongly suggests that the $\operatorname{PrP}$ sequence is intrinsically plastic. Some PrP domains may have a relatively open conformation which makes it susceptible to conversion into 
$\operatorname{Pr} \mathrm{P}^{\mathrm{Sc}}$ under appropriate physicochemical conditions [44]. However, inoculation of the $\beta$-sheet-rich recPrP isoform in mice did not transmit the disease. At the beginning of 2000, Baskakov et al. $[19,20]$ managed to partially solve the complex pathway of PrP assembly into amyloids. To study the kinetic pathway of amyloid formation, they used an unglycosylated recombinant PrP form that corresponds to the PK-resistant core of $\mathrm{PrP}^{\mathrm{Sc}}$ and found that it can adopt two abnormal $\beta$-sheet-rich isoforms ( $\beta$-oligomers and amyloid fibrils) via separate kinetic pathways. The tendency to generate either form is driven by the experimental conditions. Acidic $\mathrm{pH}$ (similar to the $\mathrm{pH}$ found in endocytic vesicles) favours the transition from $\alpha$-monomers to $\beta$-oligomers, whereas neutral $\mathrm{pH}$ promotes amyloid fibril formation [20]. These multiple misfolding pathways and the generation of distinct $\beta$ sheet-rich isoforms might explain the difficulties to generate infectious prions in vitro from pure recombinant PrP. Then, Baskakov and Legname inoculated some amyloid fibrils from purified recombinant $\operatorname{PrP}(89-231)$ in the brain of $\operatorname{Tg}(\operatorname{PrP} 89$ 231) transgenic mice that express a truncated PrP variant corresponding to the PK-resistant core. After 580 days of incubation, all injected mice were sick and showed neurological symptoms reminiscent of prion diseases. Analysis of brain tissue sections revealed spongiosis, astrocytic gliosis, and the presence of PK-resistant $\operatorname{PrP}^{S c}$ [45]. At the second passage, brain extracts from these mice were inoculated to both $\operatorname{Tg}(\operatorname{PrP} 89-231)$ and wt FVB mice. Both types of mice showed clinical signs and the biochemical features of prion disease after 150 days (FVB mice) and 250 days ( $\operatorname{Tg}(\operatorname{PrP} 89$ 231) animals) of incubation. These findings indicate that a new prion strain can be generated from pure recombinant PrP designated "synthetic mammalian prions" and that it can induce a transmissible neurodegenerative disease in transgenic mice. Subsequent in vivo experiments with various synthetic prion strains obtained from recombinant PrP fibrils demonstrated that conformationally stable recombinant amyloids produced more stable prion strains with a longer incubation time, whereas more labile amyloids generated less stable strains with a shorter incubation time [46]. One major criticism to this work is that the recombinant fibrils were first injected in transgenic animals that overexpress PrP and not in wild-type mice. Thus, the inoculation of recombinant fibrils might have resulted in an acceleration of preexisting conditions produced by transgenesis as it is the case for transgenic mice that overexpress normal or mutated $\operatorname{PrP}[31,36]$. However, injection of recombinant hamster $\operatorname{PrP}$ (recPrPHa) fibrils in wild-type Golden Syrian hamsters provided strong evidence that fibrils can induce transmissible disease de novo [47], although $100 \%$ success rate was only achieved at the second passage and was correlated with the presence of $\operatorname{Pr} \mathrm{P}^{\mathrm{Sc}}$ in the brain. The animals showed clear signs of transmissible spongiform encephalopathy (TSE), and the unique clinical course and neuropathological features suggested that a new prion disease was induced by recPrPHa fibrils. This new prion strain was designated as SSLOW due to the very long disease incubation time. These experiments are in strong favour of the protein-only hypothesis; however, it remains to be elucidated how recombinant $\operatorname{PrP}$ fibrils trigger the formation of transmissible $\mathrm{PrP}^{\mathrm{Sc}}$. The predominant hypothesis, which is based on the "template-assisted" mechanism of propagation, is that the preparation of recombinant PrP fibrils might have included some minute amount of $\operatorname{PrP}^{\mathrm{Sc}}$ (Figure 2(a)) that was responsible for the disease. This could also explain the long incubation time and the lower than $100 \%$ transmissibility at the first passage. However, recent work by Makarava et al. $[48,49]$ suggests a new templating mechanism, called "deformed templating" (Figure 2(b)). Three different inocula with conformationally distinct amyloid states $(0.5 \mathrm{M}$ fibrils, $2 \mathrm{M}$ fibrils and S fibrils) were prepared in vitro from purified recPrPHa [49]. After inoculation in mice, no signs of prion infection were found in animals injected with $2 \mathrm{M}$ and $\mathrm{S}$ fibrils that are reminiscent of $\operatorname{PrP}^{\mathrm{Sc}}$, whereas the less stable $0.5 \mathrm{M}$ fibrils induced a pathogenic process that eventually led to transmissible prion disease. Using the protein misfolding cyclic amplification (PMCA) technique, they showed that the $0.5 \mathrm{M}$ recPrPHa fibrils used to inoculate wild-type animals did not contain classical $\operatorname{PrP}^{\mathrm{Sc}}$. However, these fibrils gave rise to an atypical proteinase K-resistant PrP (PrPres) that was detected using a modified PMCA procedure. This atypical transmissible PrPres has a structure that resembles that of amyloid seeds and was observed during the asymptomatic stage of the disease before the emergence of the classical $\mathrm{PrP}^{\mathrm{Sc}}$ form [49]. This work provides evidence that apparently noninfectiou amyloid fibrils with a structure different from that of $\mathrm{PrP}^{\mathrm{Sc}}$ can lead to transmissible prion disease and suggests a new mechanism of prion conversion through "deformed templating." In this model (Figure 2(b)), recombinant PrP fibrils, which have a structure that is significantly different from that of $\mathrm{PrP}^{\mathrm{Sc}}$, can progressively acquire a new folding pattern and adapt to the template of the classical PK-resistant $\operatorname{PrP}^{\mathrm{Sc}}[48,49]$.

An alternative approach to demonstrate the protein-only hypothesis was explored by Wang et al. [50] who created recombinant prions by PMCA using recombinant mouse $\operatorname{PrP}$ (purified from E. coli) in the presence of synthetic phospholipids and total liver RNA. The recombinant prions obtained in these conditions showed all the features of the pathogenic PrP isoform, especially the protease resistance and transmissibility in wild-type CD-1 mice that succumbed to prion disease in about 150 days. This experiment provides strong evidence in support of the protein-only hypothesis because prions with high infectivity titre could be generated in vitro from well-defined components. It also illustrates the key role of lipids and RNA as cofactors to facilitate PrP conversion. Recently, Deleault et al. identified phosphatidylethanolamine as the single cofactor required to facilitate the conversion of recombinant $\mathrm{PrP}$ into infectious recombinant $\mathrm{PrP}^{\mathrm{Sc}}$ during PMCA $[51,52]$.

\section{Extending the Prion Concept to Other Neurodegenerative Diseases: The Prionopathy World}

During the last decades, many publications have shown that neurodegenerative disorders as diverse as Alzheimer's, 


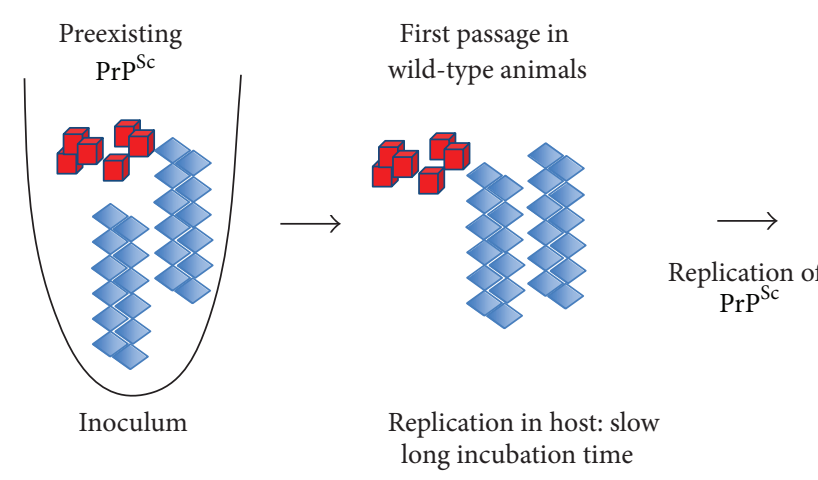

(a)

$$
\text { No } \operatorname{PrP} \mathrm{Pc}^{\mathrm{c}}
$$

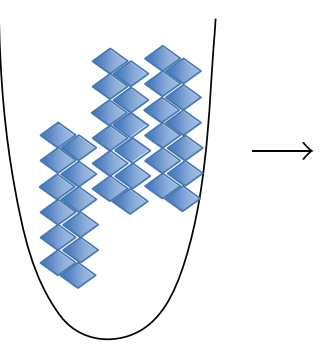

Transmission less than 100\%
Second and third passage in wild-type animals

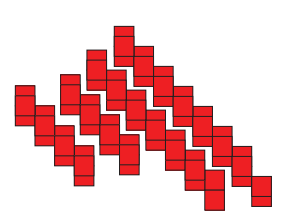

Replication in host: fast shorter incubation time

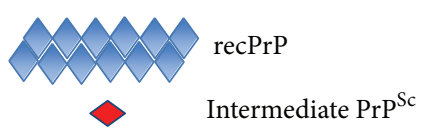

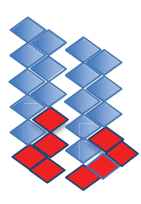
Conformational switching (a)

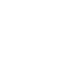

Classical $\mathrm{PrP}^{\mathrm{Sc}}$
Transmission $100 \%$

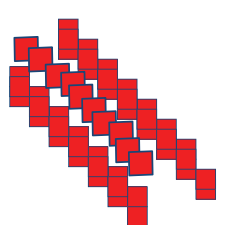

Accumulation of classic $\operatorname{Pr} \mathrm{P}^{\mathrm{Sc}}$

(b)

Figure 2: Schematic representation of two possible mechanisms of de novo propagation of prions from recPrP fibrils. (a) In this model, the preparation of recPrP fibrils contains very small amounts of classical $\operatorname{PrP}^{S c}$. A long incubation time is required to amplify and propagate in vivo this minute amount of $\operatorname{PrP}^{\mathrm{Sc}}$. (b) The second model ("deformed templating" mechanism) hypothesizes that there is no classical PrP $\mathrm{P}^{\mathrm{Sc}}$ in the fibril preparation and that recPrP fibrils can be converted into PrPres ( $\mathrm{PrP}^{\mathrm{Sc}}$-like structures) with low efficiency. After several passages, these $\mathrm{PrP}^{\mathrm{Sc}}$-like structures progressively adopt the structural features of classical $\mathrm{PrP}^{\mathrm{Sc}}$. Schema adapted from Makarava et al., 2011 [48].

Parkinson's, Huntington's, and Creutzfeldt-Jakob disease share a common pathogenic mechanism involving the aggregation and deposition of misfolded proteins. Although the type of aggregated proteins is disease specific (Table 1), they all share a "prion-like" mechanism of cell-cell propagation, with similar pathways of protein aggregation that involve oligomeric species leading to fibril formation and amyloid deposition. For instance, several studies have investigated the putative prion-like mechanism involved in the transmission of misfolded amyloid beta $(\mathrm{A} \beta)$ (Table 1 ) by inoculating brain extracts from patients with Alzheimer's disease (AD brain tissues) in several animal models. In marmoset, a nonhuman primate, amyloid plaques were induced 6-7 years after inoculation of $\mathrm{AD}$ brain tissue [53]. These plaques were composed of aggregated $\mathrm{A} \beta$ peptides similar to those found in the host, and $A \beta$ deposition was not restricted to the injection site, suggesting diffusion of the newly formed aggregates. The experiment could be successfully reproduced in Tg2576 transgenic mice that express the $\beta$-amyloid precursor protein (APP) with the Swedish mutation corresponding to the familial form of AD. Specifically, intracerebral injection of $\mathrm{AD}$ brain tissue in these animals led to a peculiar distribution of $\mathrm{A} \beta$ deposits $[54,55]$. Five months after injection, the $\mathrm{A} \beta$ aggregates were localized only in the ipsilateral side, whereas after 12 months senile plaques and vascular deposits were detected in both hemispheres, suggesting spreading of the aggregates. The use of other transgenic mouse models (APP23 and APP/PS1 animals) [56] showed that the brain $\mathrm{A} \beta$ deposit profiles vary with the host and the brain extracts used to induce amyloidosis, similar to what was observed with different prion strains [56-58]. Altogether these results clearly indicate that inoculation of brain extracts containing preformed $A \beta$ seeds accelerates the formation of new $A \beta$ deposits in vivo, in transgenic mice and non-human primates. They also support the hypothesis of a transmissible origin of AD. Remarkably, Stohr and coworkers induced cerebral $\beta$-amyloidosis by inoculating purified $\mathrm{A} \beta$ aggregates derived from brain or aggregates composed of synthetic $A \beta$ peptides in $\operatorname{Tg}$ (APP23:Gfap-luc) mice [65]. Monitoring of $\mathrm{A} \beta$ deposition in live $\operatorname{Tg}(\mathrm{APP} 23:$ Gfap-luc) mice by using bioluminescence imaging showed that $A \beta$ aggregates selfpropagate as prions.

Similar findings were reported concerning the induction of Tau aggregates [59] in the brain of transgenic mice that 
TABLE 1: Prion model of induction described for neurodegenerative diseases.

\begin{tabular}{|c|c|c|c|c|c|c|}
\hline Disease & $\begin{array}{l}\text { Normally folded } \\
\text { protein } \\
\text { "Precursor" }\end{array}$ & $\begin{array}{l}\text { Abnormally folded } \\
\text { protein } \\
\text { "Prion form" }\end{array}$ & $\begin{array}{l}\text { Protein aggregates } \\
\text { detected }\end{array}$ & Seeding inoculum & $\begin{array}{l}\text { Prion-like propagation } \\
\text { in mammals }\end{array}$ & References \\
\hline CJD/scrapie & e $\operatorname{PrP}{ }^{C}$ & $\mathrm{PrP}^{\mathrm{Sc}}$ & $\begin{array}{l}\mathrm{PrP}^{\mathrm{Sc}} \text { deposits } \\
\text { plaques }\end{array}$ & $\begin{array}{l}\text { Various mammalian } \\
\text { prions and recPrP } \\
\text { fibrils }\end{array}$ & $\begin{array}{l}\text { WT and Tg mice } \\
\text { Non-human primates }\end{array}$ & $\begin{array}{c}{[32,33,37-40]} \\
{[45-50]}\end{array}$ \\
\hline $\begin{array}{l}\text { Alzheimer } \\
(\mathrm{AD})\end{array}$ & $\begin{array}{l}\text { Amyloid precursor } \\
\text { protein (APP) }\end{array}$ & $\begin{array}{l}\text { Amyloid beta } \\
\text { peptides } \mathrm{A} \beta\end{array}$ & $\mathrm{A} \beta$ plaques & $\begin{array}{l}\text { Human } \mathrm{AD} \text { and } \mathrm{Tg} \\
\text { mice brain extracts } \\
\text { blood }\end{array}$ & $\begin{array}{l}\text { Marmosets } \\
\text { TgAPP2576 } \\
\text { TgAPP23, TgAPP/PS1 }\end{array}$ & [53-58] \\
\hline Tauopathies & s Tau & Tau aggregates & $\begin{array}{l}\text { Neurofibrillary } \\
\text { tangles (NFTs) }\end{array}$ & $\begin{array}{l}\mathrm{Tg}(\mathrm{HuTauP} 301 \mathrm{~S}) \\
\text { brain extracts }\end{array}$ & $\operatorname{Tg}(w t \mathrm{Tau})$ & {$[59,60]$} \\
\hline \multirow{2}{*}{$\begin{array}{l}\text { Parkinson } \\
\text { (PD) }\end{array}$} & \multirow[t]{2}{*}{$\alpha$-Synuclein } & \multirow[t]{2}{*}{$\begin{array}{l}\alpha \text {-Synuclein } \\
\text { aggregates }\end{array}$} & \multirow[t]{2}{*}{ Lewy bodies } & \multirow{2}{*}{$\begin{array}{l}\text { Human } \\
\text { preformed } \\
\alpha \text {-Syn fibrils }\end{array}$} & $\begin{array}{l}\text { (i) Fetal tissue grafts in } \\
\text { human PD patients }\end{array}$ & {$[61,62]$} \\
\hline & & & & & $\begin{array}{l}\text { (ii) } \operatorname{Tg}(\alpha-\text { SynA53T }) \\
\text { and WT mice }\end{array}$ & {$[63,64]$} \\
\hline
\end{tabular}

express wild-type human Tau after intracerebral injection of brain extracts from old $\mathrm{Tg}(\mathrm{HuTauP} 301 \mathrm{~S})$ mice containing insoluble Tau aggregates. Neurofibrillary tangles, neuropil threads, and coiled bodies could be visualized not only in neurons but also in oligodendrocytes of the injected animals. In addition, mouse Tau can coaggregate with human Tau P301S, indicating cross-species seeding [60].

The hallmark of Parkinson's disease (PD) is the presence in the brain of Lewy bodies and Lewy neurites that contain high amounts of aggregates of misfolded $\alpha$-Synuclein $(\alpha$-Syn). In the dual-hit hypothesis proposed by Hawkes and coworkers, PD originates in the nose and foregut after inhalation/ingestion of an unknown neurotropic pathogen and then aggregates spread throughout the nervous system with a stereotypic pattern following unmyelinated axons [66]. This theory is based on extensive postmortem analyses of patients with $\mathrm{PD}$ that identified the olfactory bulb and enteric plexus of the stomach as early sites of Lewy pathology, and also on evidence of olfactory and autonomic dysfunction as early nonmotor PD symptoms [66]. Based on this hypothesis, Luk et al. [63] have stereotaxically injected preformed recombinant $\alpha$-Syn fibrils in the cortex and striatum of $\operatorname{Tg}(\alpha$-SynA53T $)$ mice that express human $\alpha$-Syn harbouring the A53T mutation related to familiar PD and showed that $\alpha$-Syn aggregates can spread in the tissues with a prion-like mechanism of propagation. Similarly, a single intrastriatal inoculation of synthetic $\alpha$-Syn fibrils in wildtype nontransgenic mice led to the cell-to-cell transmission of pathologic $\alpha$-Syn and Parkinson's-like Lewy pathology in anatomically interconnected regions. Accumulation of toxic aggregates in these mice triggered a progressive loss of dopamine neurons in the substantia nigra and a reduced dopamine levels culminating in motor deficits [64]. Remarkably, experiments of transplantation of fetal cells in PD subjects showed the presence of Lewy body-like inclusions 14 years after grafting that stained positively for $\alpha$-Syn and ubiquitin and had reduced immunostaining for dopamine transporter [61]. This result was confirmed in other PD subjects transplanted with fetal mesencephalic dopaminergic neurons (11-16 years) who developed $\alpha$-Syn-positive Lewy bodies in grafted neurons [62]. These results suggest a hostto-graft disease propagation mechanism with implications for cell-based therapies $[61,62]$.

\section{Conclusion}

These last years have been marked by the end of the controversy about the protein-only hypothesis concerning prion diseases. In addition, a growing number of studies have shown that other amyloidogenic proteins implicated in various neurodegenerative disorders can propagate in vivo with a prion-like mechanism. We witness the opening of a new field of research in neurodegenerative disorders $[67,68]$, and the lessons learned from prion diseases will help scientists develop new strategies for diagnostic and therapeutic approaches for other neurodegenerative disorders.

\section{References}

[1] S. B. Prusiner, "Novel proteinaceous infectious particles cause scrapie," Science, vol. 216, no. 4542, pp. 136-144, 1982.

[2] D. Dormont, "Prion diseases: pathogenesis and public health concerns," FEBS Letters, vol. 529, no. 1, pp. 17-21, 2002.

[3] R. G. Will, J. W. Ironside, M. Zeidler et al., "A new variant of Creutzfeldt-Jakob disease in the UK," The Lancet, vol. 347, no. 9006, pp. 921-925, 1996.

[4] A. H. Peden, M. W. Head, D. L. Ritchie, P. J. E. Bell, and P. J. W. Ironside, "Preclinical vCJD after blood transfusion in a PRNP codon 129 heterozygous patient," The Lancet, vol. 364, no. 9433, pp. 527-529, 2004.

[5] B. Sibbald, "UK patient first to contract vCJD via blood transfusion," Canadian Medical Association Journal, vol. 170, no. 7, p. 1087, 2004.

[6] S. J. Wroe, S. Pal, D. Siddique et al., "Clinical presentation and pre-mortem diagnosis of variant Creutzfeldt-Jakob disease associated with blood transfusion: a case report," The Lancet, vol. 368, no. 9552, pp. 2061-2067, 2006.

[7] D. C. Gajdusek and C. J. Gibbs Jr., "Slow, latent and temperate virus infections of the central nervous system," Research Publications-Association for Research in Nervous and Mental Disease, vol. 44, pp. 254-280, 1968. 
[8] R. H. Kimberlin, “Scrapie agent: prions or virinos?” Nature, vol. 297, no. 5862, pp. 107-108, 1982.

[9] I. H. Pattison and K. M. Jones, "The possible nature of the transmissible agent of scrapie," Veterinary Record, vol. 80, no. 1, pp. 2-9, 1967.

[10] T. Alper, W. A. Cramp, D. A. Haig, and M. C. Clarke, "Does the agent of scrapie replicate without nucleic acid?” Nature, vol. 214, no. 5090, pp. 764-766, 1967.

[11] J. S. Griffith, "Self-replication and scrapie," Nature, vol. 215, no. 5105, pp. 1043-1044, 1967

[12] S. B. Prusiner, M. P. McKinley, D. F. Groth et al., "Scrapie agent contains a hydrophobic protein," Proceedings of the National Academy of Sciences of the United States of America, vol. 78, no. 11, pp. 6675-6679, 1981.

[13] S. B. Prusiner, "Prions," Proceedings of the National Academy of Sciences of the United States of America, vol. 95, no. 23, pp. 13363-13383, 1998.

[14] R. Riek, S. Hornemann, G. Wider, M. Billeter, R. Glockshuber, and K. Wuthrich, "NMR structure of the mouse prion protein domain PrP(121-231)," Nature, vol. 382, no. 6587, pp. 180-182, 1996.

[15] K.-M. Pan, M. Baldwin, J. Nguyen et al., "Conversion of $\alpha$ helices into $\beta$-sheets features in the formation of the scrapie prion proteins," Proceedings of the National Academy of Sciences of the United States of America, vol. 90, no. 23, pp. 10962-10966, 1993.

[16] C. Govaerts, H. Wille, S. B. Prusiner, and F. E. Cohen, "Evidence for assembly of prions with left-handed $\beta$-helices into trimers," Proceedings of the National Academy of Sciences of the United States of America, vol. 101, no. 22, pp. 8342-8347, 2004.

[17] J. R. Silveira, G. J. Raymond, A. G. Hughson et al., “The most infectious prion protein particles," Nature, vol. 437, no. 7056, pp. 257-261, 2005.

[18] G. P. Saborio, B. Permanne, and C. Soto, "Sensitive detection of pathological prion protein by cyclic amplification of protein misfolding," Nature, vol. 411, no. 6839, pp. 810-813, 2001.

[19] I. V. Baskakov, G. Legname, S. B. Prusiner, and F. E. Cohen, "Folding of prion protein to its native alpha-helical conformation is under kinetic control," The Journal of Biological Chemistry, vol. 276, no. 23, pp. 19687-19690, 2001.

[20] I. V. Baskakov, G. Legname, M. A. Baldwin, S. B. Prusiner, and F. E. Cohen, "Pathway complexity of prion protein assembly into amyloid," The Journal of Biological Chemistry, vol. 277, no. 24, pp. 21140-21148, 2002.

[21] B. Février, D. Vilette, H. Laude, and G. Raposo, "Exosomes: a bubble ride for prions?” Traffic, vol. 6, no. 1, pp. 10-17, 2005.

[22] L. J. Vella, R. A. Sharples, V. A. Lawson, C. L. Masters, R. Cappai, and A. F. Hill, "Packaging of prions into exosomes is associated with a novel pathway of PrP processing," Journal of Pathology, vol. 211, no. 5, pp. 582-590, 2007.

[23] B. Caughey and P. T. Lansbury Jr., "Protofibrils, pores, fibrils, and neurodegeneration: separating the responsible protein aggregates from the innocent bystanders," Annual Review of Neuroscience, vol. 26, pp. 267-298, 2003.

[24] S. Simoneau, H. Rezaei, N. Salès et al., "In vitro and in vivo neurotoxicity of prion protein oligomers," PLoS Pathogens, vol. 3, no. 8, article e125, 2007.

[25] J. A. Hainfeller, S. Brantner-Inthaler, L. Cervenakova et al., "The original Gerstmann-Straussler-Scheinker family of austria: divergent clinicopathological phenotypes but constant $\operatorname{PrP}$ genotype," Brain Pathology, vol. 5, no. 3, pp. 201-211, 1995.
[26] M. H. Groschup and A. Buschmann, "Rodent models for prion diseases," Veterinary Research, vol. 39, no. 4, article 32, 2008.

[27] I. H. Solomon, J. A. Schepker, and D. A. Harris, "Prion neurotoxicity: insights from prion protein mutants," Current Issues in Molecular Biology, vol. 12, no. 2, pp. 51-61, 2010.

[28] H. Bueler, A. Aguzzi, A. Sailer et al., "Mice devoid of PrP are resistant to scrapie," Cell, vol. 73, no. 7, pp. 1339-1347, 1993.

[29] S. B. Prusiner, D. Groth, A. Serban et al., "Ablation of the prion protein $(\mathrm{PrP})$ gene in mice prevents scrapie and facilitates production of anti-PrP antibodies," Proceedings of the National Academy of Sciences of the United States of America, vol. 90, no. 22, pp. 10608-10612, 1993.

[30] G. R. Mallucci, M. D. White, M. Farmer et al., “Targeting cellular prion protein reverses early cognitive deficits and neurophysiological dysfunction in prion-infected mice," Neuron, vol. 53, no. 3, pp. 325-335, 2007.

[31] D. Westaway, S. J. DeArmond, J. Cayetano-Canlas et al., "Degeneration of skeletal muscle, peripheral nerves, and the central nervous system in transgenic mice overexpressing wildtype prion proteins," Cell, vol. 76, no. 1, pp. 117-129, 1994.

[32] C. J. Sigurdson, K. P. R. Nilsson, S. Hornemann et al., "De novo generation of a transmissible spongiform encephalopathy by mouse transgenesis," Proceedings of the National Academy of Sciences of the United States of America, vol. 106, no. 1, pp. 304309, 2009.

[33] J. C. Watts, K. Giles, J. Stöhr et al., "Spontaneous generation of rapidly transmissible prions in transgenic mice expressing wild-type bank vole prion protein," Proceedings of the National Academy of Sciences of the United States of America, vol. 109, no. 9, pp. 3498-3503, 2012.

[34] K. K. Hsiao, M. Scott, D. Foster, D. F. Groth, S. J. DeArmond, and S. B. Prusiner, "Spontaneous neurodegeneration in transgenic mice with mutant prion protein," Science, vol. 250, no. 4987, pp. 1587-1590, 1990.

[35] G. C. Telling, T. Haga, M. Torchia, P. Tremblay, S. J. DeArmond, and S. B. Prusiner, "Interactions between wild-type and mutant prion proteins modulate neurodegeneration in transgenic mice," Genes and Development, vol. 10, no. 14, pp. 1736-1750, 1996.

[36] R. Chiesa, P. Piccardo, B. Ghetti, and D. A. Harris, "Neurological illness in transgenic mice expressing a prion protein with an insertional mutation," Neuron, vol. 21, no. 6, pp. 1339-1351, 1998.

[37] R. Chiesa, P. Piccardo, S. Dossena et al., "Bax deletion prevents neuronal loss but not neurological symptoms in a transgenic model of inherited prion disease," Proceedings of the National Academy of Sciences of the United States of America, vol. 102, no. 1, pp. 238-243, 2005.

[38] Y. Friedman-Levi, Z. Meiner, T. Canello et al., "Fatal prion disease in a mouse model of genetic E200K Creutzfeldt-Jakob disease," PLoS Pathogens, vol. 7, no. 11, Article ID e1002350, 2011.

[39] W. S. Jackson, A. W. Borkowski, H. Faas et al., "Spontaneous generation of prion infectivity in fatal familial insomnia knockin mice," Neuron, vol. 63, no. 4, pp. 438-450, 2009.

[40] M. Fischer, T. Rulicke, A. Raeber et al., "Prion protein (PrP) with amino-proximal deletions restoring susceptibility of $\operatorname{PrP}$ knockout mice to scrapie," EMBO Journal, vol. 15, no. 6, pp. 1255-1264, 1996.

[41] D. W. Colby, R. Wain, I. V. Baskakov et al., "Protease-sensitive synthetic prions," PLoS Pathogens, vol. 6, no. 1, Article ID e1000736, 2010. 
[42] P. Gambetti, G. Puoti, and W.-Q. Zou, "Variably proteasesensitive prionopathy: a novel disease of the prion protein," Journal of Molecular Neuroscience, vol. 45, no. 3, pp. 422-424, 2011.

[43] I. Mehlhorn, D. Groth, J. Stöckel et al., "High-level expression and characterization of a purified 142-residue polypeptide of the prion protein," Biochemistry, vol. 35, no. 17, pp. 5528-5537, 1996.

[44] H. Zhana, J. Stöckel, I. Mehlhorn et al., "Physical studies of conformational plasticity in a recombinant prion protein," Biochemistry, vol. 36, no. 12, pp. 3543-3553, 1997.

[45] G. Legname, I. V. Baskakov, H.-O. B. Nguyen et al., "Synthetic mammalian prions," Science, vol. 305, no. 5684, pp. 673-676, 2004.

[46] D. W. Colby, K. Giles, G. Legname et al., "Design and construction of diverse mammalian prion strains," Proceedings of the National Academy of Sciences of the United States of America, vol. 106, no. 48, pp. 20417-20422, 2009.

[47] N. Makarava, G. G. Kovacs, O. Bocharova et al., "Recombinant prion protein induces a new transmissible prion disease in wildtype animals," Acta Neuropathologica, vol. 119, no. 2, pp. 177-187, 2010.

[48] N. Makarava, G. G. Kovacs, R. Savtchenko et al., "Genesis of mammalian prions: from non-infectious amyloid fibrils to a transmissible prion disease," PLoS Pathogens, vol. 7, no. 12, Article ID e1002419, 2011.

[49] N. Makarava, G. G. Kovacs, R. Savtchenko et al., "A new mechanism for transmissible prion diseases," Journal of Neuroscience, vol. 32, no. 21, pp. 7345-7355, 2012.

[50] F. Wang, X. Wang, C.-G. Yuan, and J. Ma, “Generating a prion with bacterially expressed recombinant prion protein," Science, vol. 327, no. 5969, pp. 1132-1135, 2010.

[51] N. R. Deleault, J. R. Piro, D. J. Walsh et al., "Isolation of phosphatidylethanolamine as a solitary cofactor for prion formation in the absence of nucleic acids," Proceedings of the National Academy of Sciences of the United States of America, no. 22, pp. 8546-8551, 2012.

[52] N. R. Deleault, D. J. Walsh, J. R. Piro et al., "Cofactor molecules maintain infectious conformation and restrict strain properties in purified prions," Proceedings of the National Academy of Sciences of the United States of America, vol. 109, no. 28, pp. E1938-E1946, 2012.

[53] H. F. Baker, R. M. Ridley, L. W. Duchen, T. J. Crow, and C. J. Bruton, "Induction of $\beta(\mathrm{A} 4)$-amyloid in primates by injection of Alzheimer's disease brain homogenate-comparison with transmission of spongiform encephalopathy," Molecular Neurobiology, vol. 8, no. 1, pp. 25-39, 1994.

[54] M. D. Kane, W. J. Lipinski, M. J. Callahan et al., "Evidence for seeding of $\beta$-amyloid by intracerebral infusion of Alzheimer brain extracts in $\beta$-amyloid precursor protein-transgenic mice," Journal of Neuroscience, vol. 20, no. 10, pp. 3606-3611, 2000.

[55] L. C. Walker, F. Bian, M. J. Callahan, W. J. Lipinski, R. A. Durham, and H. LeVine, "Modeling Alzheimer's disease and other proteopathies in vivo: is seeding the key?" Amino Acids, vol. 23, no. 1-3, pp. 87-93, 2002.

[56] M. Meyer-Luehmann, J. Coomaraswamy, T. Bolmont et al., "Exogenous induction of cerebral $\beta$-amyloidogenesis is governed bf agent and host," Science, vol. 313, no. 5794, pp. 17811784, 2006.

[57] Y. S. Eisele, U. Obermüller, G. Heilbronner et al., "Peripherally applied $\mathrm{A} \beta$-containing inoculates induce cerebral $\beta$ amyloidosis," Science, vol. 330, no. 6006, pp. 980-982, 2010.
[58] R. Morales, C. Duran-Aniotz, J. Castilla, L. D. Estrada, and C. Soto, "De novo induction of amyloid- $\beta$ deposition in vivo," Molecular Psychiatry, vol. 17, no. 12, pp. 1347-1353, 2011.

[59] F. Clavaguera, T. Bolmont, R. A. Crowther et al., "Transmission and spreading of tauopathy in transgenic mouse brain," Nature Cell Biology, vol. 11, no. 7, pp. 909-913, 2009.

[60] A. de Calignon, M. Polydoro, M. Suárez-Calvet et al., "Propagation of tau pathology in a model of early Alzheimer's disease," Neuron, vol. 73, no. 4, pp. 685-697, 2012.

[61] J. H. Kordower, Y. Chu, R. A. Hauser, T. B. Freeman, and C. W. Olanow, "Lewy body-like pathology in long-term embryonic nigral transplants in Parkinson's disease," Nature Medicine, vol. 14, no. 5, pp. 504-506, 2008.

[62] J.-Y. Li, E. Englund, J. L. Holton et al., "Lewy bodies in grafted neurons in subjects with Parkinson's disease suggest host-tograft disease propagation," Nature Medicine, vol. 14, no. 5, pp. 501-503, 2008.

[63] K. C. Luk, V. M. Kehm, B. Zhang, P. O’Brien, J. Q. Trojanowski, and V. M. Lee, "Intracerebral inoculation of pathological alphasynuclein initiates a rapidly progressive neurodegenerative alpha-synucleinopathy in mice," The Journal of Experimental Medicine, no. 5, pp. 975-986, 2012.

[64] K. C. Luk, V. Kehm, J. Carroll et al., "Pathological alphasynuclein transmission initiates Parkinson-like neurodegeneration in nontransgenic mice," Science, vol. 338, no. 6109, pp. 949953, 2012.

[65] J. Stohr, J. C. Watts, Z. L. Mensinger et al., "Purified and synthetic Alzheimer's amyloid beta (Abeta) prions," Proceedings of the National Academy of Sciences of the United States of America, no. 27, pp. 11025-11030, 2012.

[66] C. H. Hawkes, K. Del Tredici, and H. Braak, "Parkinson's disease: the dual hit theory revisited," Annals of the New York Academy of Sciences, vol. 1170, pp. 615-622, 2009.

[67] H. Y. E. Chan, J. M. Warrick, I. Andriola, D. Merry, and N. M. Bonini, "Aggregated polyglutamine peptides delivered to nuclei are toxic to mammalian cells," Human Molecular Genetics, vol. 11, no. 23, pp. 2905-2917, 2002.

[68] P.-H. Ren, J. E. Lauckner, I. Kachirskaia, J. E. Heuser, R. Melki, and R. R. Kopito, "Cytoplasmic penetration and persistent infection of mammalian cells by polyglutamine aggregates," Nature Cell Biology, vol. 11, no. 2, pp. 219-225, 2009. 

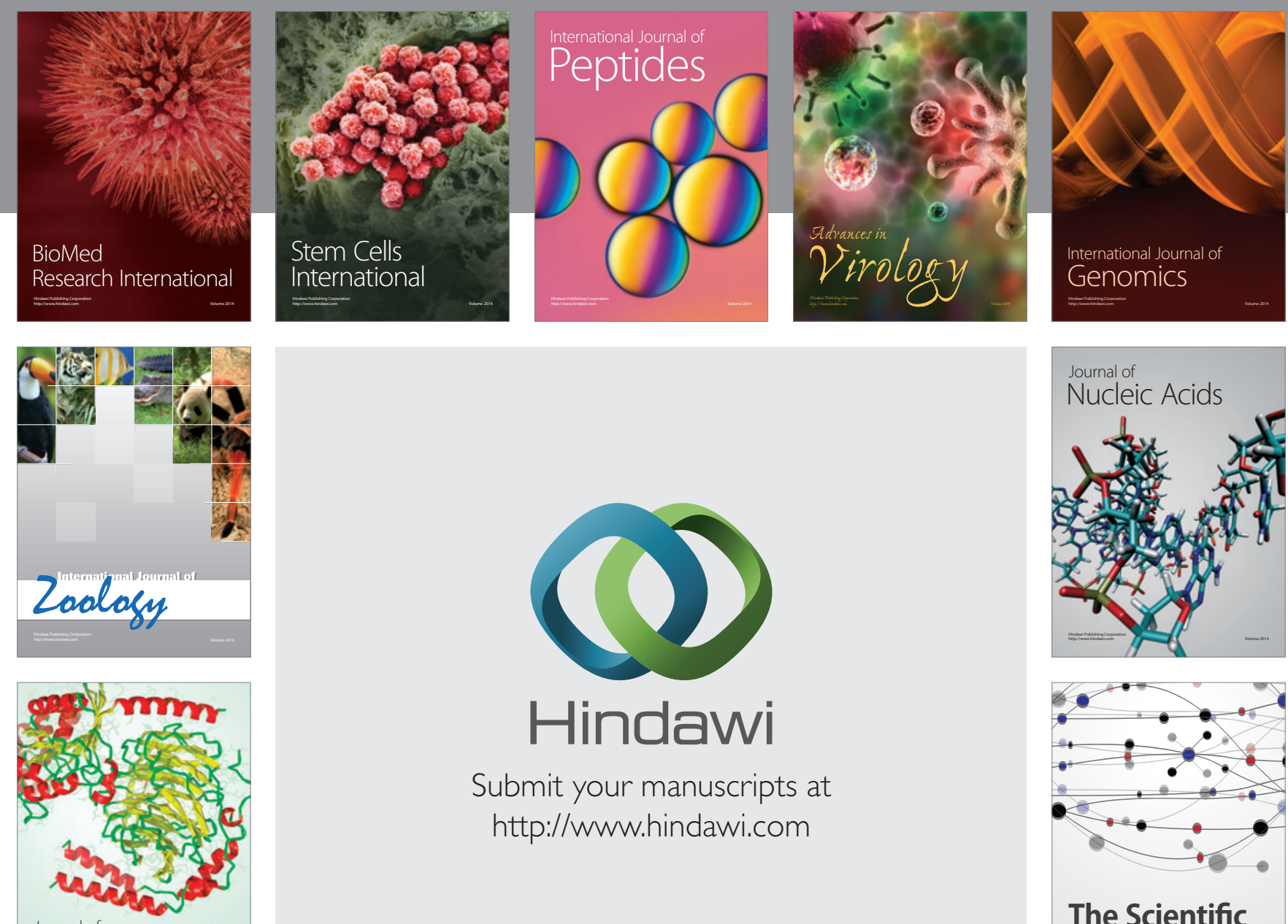

Submit your manuscripts at

http://www.hindawi.com

Journal of
Signal Transduction
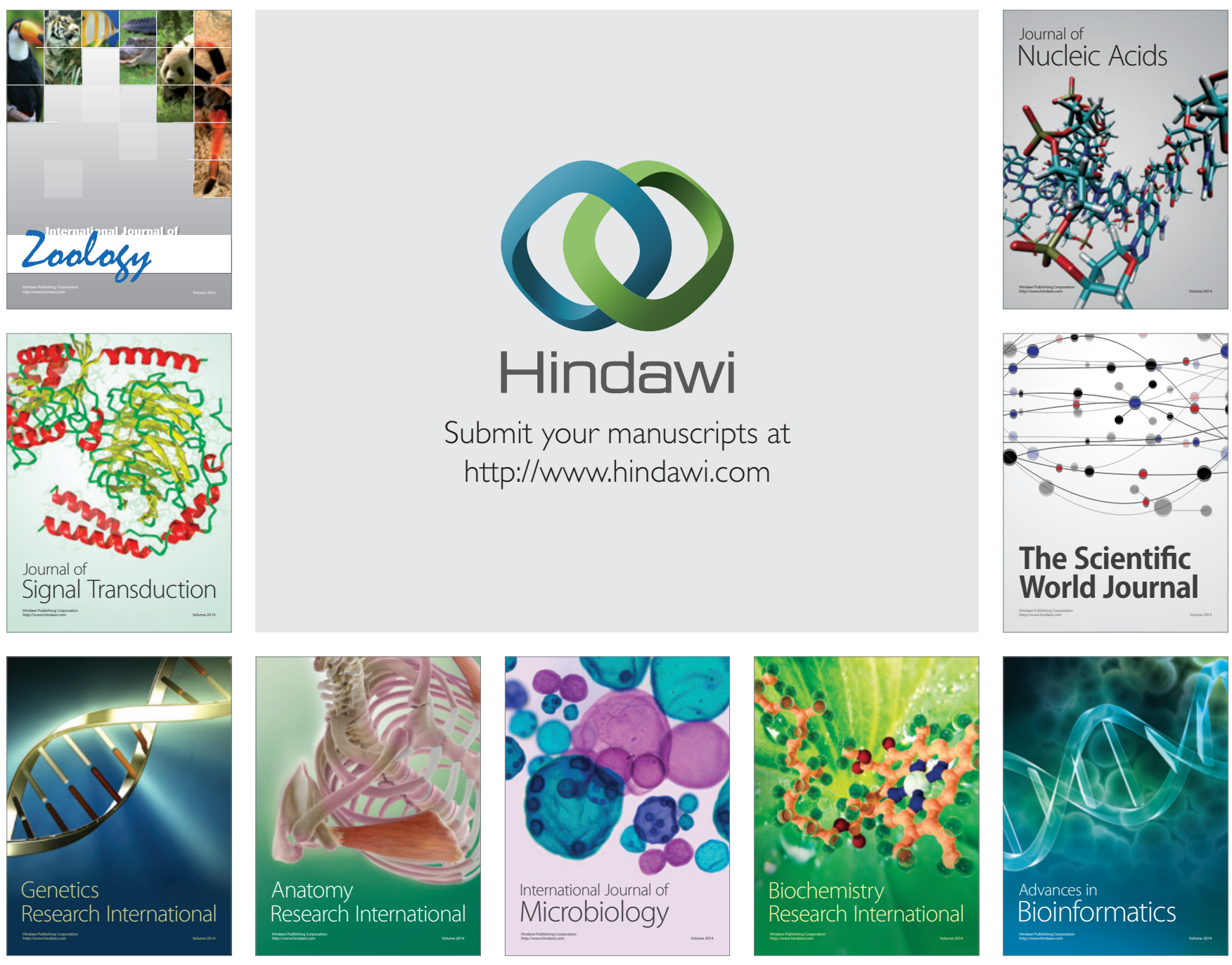

The Scientific World Journal
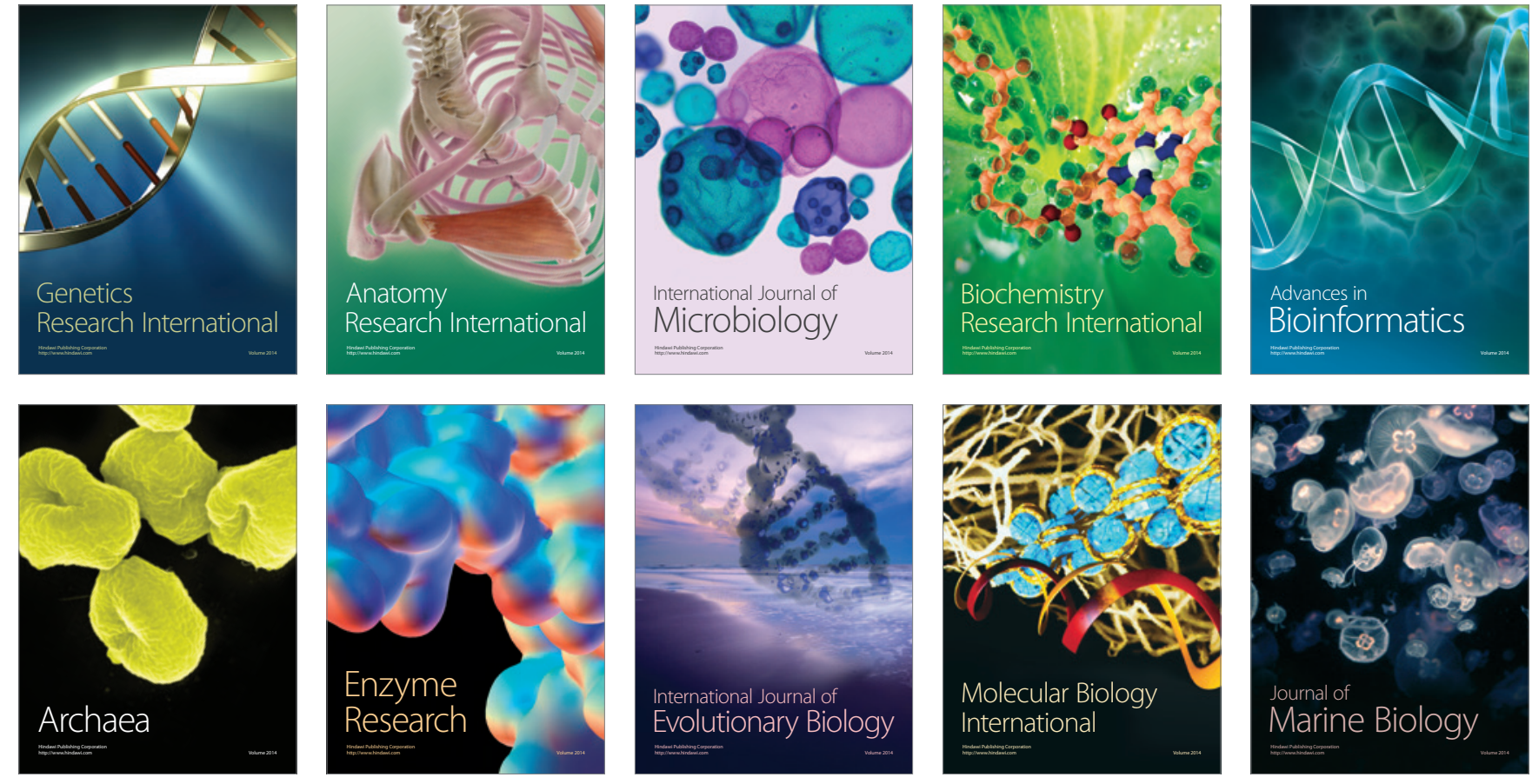